\title{
Lever height and free operant avoidance learning in rats
}

\author{
ALBERT E. ROBERTS and JOHN T. RENDLEMAN, JR. \\ Catawba College, Salisbury, North Carolina 28144
}

\begin{abstract}
Two experiments examined the free operant avoidance behavior of rats trained with a lever placed either $6 \mathrm{~cm}$ or $1.9 \mathrm{~cm}$ above the floor grids. In each experiment, better first-session performance was found with the lower lever. But Experiment 2 showed that this initial advantage faded with additional training, and similar acquisition curves were obtained with the two levers. The results suggested that the lower lever, permitting the rats to take advantage of a natural defensive reaction to shock (running), facilitated initial contacts with the lever but had little influence in the learning to use the lever to develop shock postponement behavior.
\end{abstract}

Bolles, in his now familiar analysis of avoidance learning $(1970,1971)$, argued that an important variable controlling shock avoidance learning is the avoidance requirement itself. Briefly stated, the more compatible the response requirement is with one of an organism's set of natural defensive reactions (i.e., flight, fight, freeze), the more rapid is the avoidance learning. For example, Grossen and Kelly (1972, Experiment 2) showed that requiring a response compatible with the thigmotaxic tendency of the rat (movement while in contact with an object, such as a wall) led to better avoidance of shock than one incompatible with thigmotaxis. Moreover, when subjects were given an option of performing either the compatible or the incompatible response, the overwhelming choice was the former.

One area for which Bolles' $(1970,1971)$ analysis has had important implications is that of free operant avoidance learning (Sidman, 1953). Under this avoidance procedure, each criterion response postpones a shock for a prescribed period, the R-S interval; otherwise, shock is given regularly, the S-S interval. Here, too, the selection of the response can influence the rate of avoidance acquisition. Riess (1971, Experiment 1) compared shuttle responding (presumably a natural reaction compatible with flight) and leverpressing (a nonnatural reaction) over nine 30-min sessions. Asymptotic levels of shuttle performance were obtained by the third session, whereas leverpressing performance had not approached asymptote at the end of training. Moreover, the low shock rates of the shuttle group indicated that shock avoidance had been mastered, whereas the lever group often failed to respond even at the delivery of unavoided shocks.

This research was supported by a grant from the Catawba College Faculty Research Committee awarded to the first author. Portions of Experiment 2 are based on an Honors Thesis submitted by the second author to the Department of Psychology. John Rendleman is now at Western Carolina University, Cullowhee, North Carolina. Reprints may be obtained from Albert E. Roberts, Department of Psychology, Catawba College, Salisbury, North Carolina 28144.
But leverpress avoidance, while possibly a nonnatural reaction, can be learned, albeit slowly, and a number of factors have been reported to facilitate acquisition, for example, a feedback stimulus (Bolles \& Popp, 1964), intense and/or long shocks (Hayes \& MacKinnon, 1968; Stone, 1966), relatively short S-S intervals (Leaf, 1965; Stone, 1966). Another factor may well be the height of the manipulandum to be pressed, which is subject to wide variations between experiments. For example, Sidman (1953) positioned the manipulandum about $11.4 \mathrm{~cm}$ above the grid floor in his pioneering study, and others have used placements of $10.2 \mathrm{~cm}$ (Bolles \& Popp, 1964), $9 \mathrm{~cm}$ (Riess, 1971), $7.6 \mathrm{~cm}$ (Powell, 1971), $6 \mathrm{~cm}$ (Roberts, 1978), $5 \mathrm{~cm}$ (Hineline, 1978 ), and $3.8 \mathrm{~cm}$ (Leaf, 1965) ${ }^{1}$ many did not provide this information. Lever height as a factor in avoidance acquisition has not been examined until recently and might be dismissed as trivial except for (1) the economics involved in optimizing successful leverpress avoidance learning and (2) the theoretical relevance derived from the Bolles $(1970,1971)$ position.

Considering the latter, Feldt and McCann (1977, Experiment 2) recently compared avoidance measures obtained over a 60 -min training session as a function of lever height $(19.83$ and $3.02 \mathrm{~cm})$ and shock intensity ( 1 and $2 \mathrm{~mA}$ ). Response rate with the higher lever was greater than with the lower one under the stronger shock, but response rate differences between the two levers were not reliable under the weaker shock. The high-lever/strong-shock group was viewed as having profited from shock-elicited jumping. That is, more jumping (a natural defensive reaction) occurred to the stronger shock and increased the likelihood of making contact with the higher lever. Feldt and McCann (1977) noted that most of the responses on the lower lever (irrespective of shock intensity) were a result of running; they offered the view that "running is highly compatible with the avoidance topography of the low lever position" (p. 81). Indeed, Roberts, Cooper, and Richey (1977) reported that running was common early in 
avoidance training, but they found qualitative changes in the kind of locomotor activities later in training: less movement about the chamber and more leveroriented movements (e.g., crawling back and forth over the lever). Thus, the possibility exists that leverpressing to avoid shock is not only rich in locomotor components, but may evolve from the natural flight reaction originally elicited by shock. If so, better indices of avoidance should be obtained if the lever were lowered even further than in the Feldt and McCann (1977) study, to be within the thigmotaxic path of the rat, compared with a position the rat could run around or under. The purpose of Experiment 1 was to examine avoidance performance as a function of lever height.

\section{EXPERIMENT 1}

\section{Method}

Subjects. Fourteen male and 14 female rats, descendents of Long-Evans stock, were drawn from the laboratory colony to serve as subjects. The rats were experimentally naive and weighed about $175 \mathrm{~g}$ at the beginning of the experiment.

Apparatus. Three LVE operant chambers (Model 143-20), measuring $30 \times 24 \times 26.5 \mathrm{~cm}$ (length by width by depth), were used. Each chamber was modified by placing a houselight in the center of the ceiling and removing all standard assemblies protruding into the chamber. The floor grids were brass rods $(.25 \mathrm{~cm})$ spaced $1.3 \mathrm{~cm}$ apart and parallel to the width of the lever. The levers $(2.5 \times 3 \mathrm{~cm})$ extended $2.5 \mathrm{~cm}$ into the chamber from the middle of the intelligence panel. For two chambers, the lever was $6 \mathrm{~cm}$ above the grid floor, that is, in the location manufactured by LVE (referred to as the "regular" position); the lever for the third chamber was lowered to $1.9 \mathrm{~cm}$ above the grid floor (the "lower" position). A dead weight of $36 \mathrm{~g}(.36 \mathrm{~N})$ was required to operate the microswitch of each lever. Avoidance training records over the past 2 years were examined to be certain that box differences were not present. Moreover, three rats with avoidance experience in the chamber prior to modification were tested with the lower lever; following a short adjustment period, avoidance measures before and after the modification were comparable.

A 1-mA .3-sec shock was delivered to the grids, lever, and metal sides of each chamber by a constant-current shock generator (BRS Model SG-901) via a scrambler (BRS Model SC-901). Each chamber was placed in a sound-attenuated box with a blower fan providing ventilation and background noise $(75 \mathrm{~dB}$ SPL). All programming and recording equipment was in an adjoining room.

Procedure. The rats were factorially arranged into one of four groups (each $n=7$ ) on the basis of sex and lever height. Under the avoidance schedule used, each leverpress postponed shock for $20 \mathrm{sec}$ and briefly $(.3 \mathrm{sec})$ turned off the houselight (a feedback signal), which otherwise was on during the single 60-min session. In the absence of a leverpress, shock was delivered every $5 \mathrm{sec}$. The first $10 \mathrm{~min}$ of the session was monitored to record the times elapsing between (1) the start of the session and the first leverpress (latency) and (2) the first and second leverpresses. The number of responses and unavoided shocks for the entire session were also recorded.

\section{Results and Discussion}

The results of Experiment 1 are summarized in Figure 1. ANOVA indicated that differences in response frequencies attributable to lever height, sex of the rat, or the interaction were unreliable (all Fs $<2$, ps $>.10$ ). On the other hand, reliably more shocks occurred with

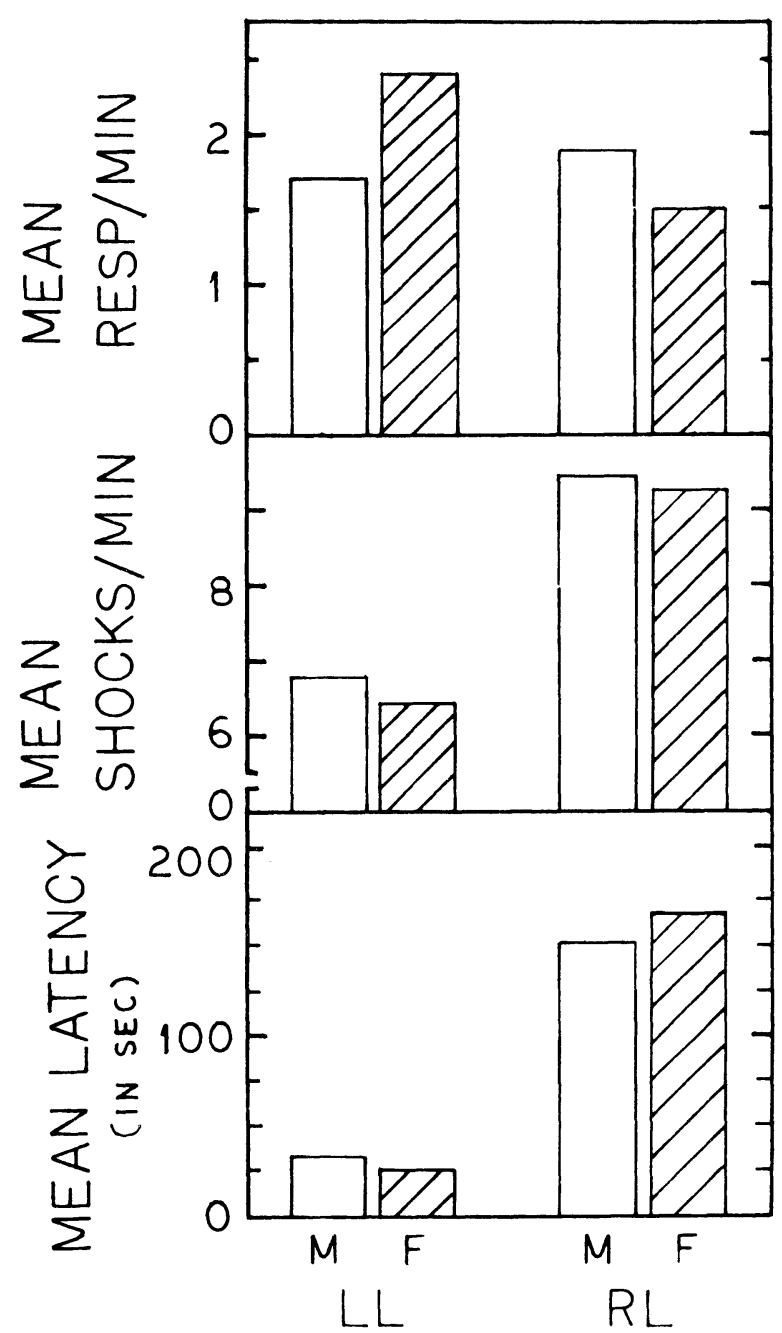

Figure 1. Mean response rates (upper panel), shock rates (middle panel), and latencies to the first response (lower panel) for the male (M) and female (F) rats trained with the lower lever (LL) or regular lever (RL).

the regular lever than with the lower lever $[F(1,24)=$ $73.49, \mathrm{p}<.001]$. Differences in shock frequencies due to sex of the rat or the Sex by Lever interaction were unreliable. The mean latency to the first response of the lower lever group $(31 \mathrm{sec})$ was significantly shorter than that of the regular lever group $(160 \mathrm{sec})[\mathrm{F}(1,24)=$ $6.97, \mathrm{p}<.025]$; other effects were nonsignificant. Since the latency could reflect the location of the rat in the chamber at the time the first shock occurred, as well as the influence of lever height, the time between the first and second responses was also analyzed. Only two rats failed to make a second response within the first $10 \mathrm{~min}$ of the session (a male and female of the regular lever groups), and ANOVA based on the times recorded for the other 24 rats indicated that the time between the first two responses was significantly less for the lower lever than for the regular lever (means of 39 and $69 \mathrm{sec}$, respectively) $[\mathrm{F}(1,22)=11.31, \mathrm{p}<.005]$; other effects were nonsignificant.

As predicted, placing the lever in a very low position 
led to earlier contact with the lever, shorter times between the first two responses, and better shock avoidance (in terms of lower shock frequencies) for the session. The failure to find differences between response rates due to lever height probably reflects the influence of "response bursts" on the response measure. Several rats trained with the regular lever gave bursts of responses to shock later in the session; bursts with the lower lever were infrequent.

These results indicated that a lowered lever contributes to better first-session avoidance performance, but a number of training sessions typically must be given to obtain asymptotic response and shock rate levels (cf. Riess, 1971; Roberts, Porter, \& Porter, 1974). It remains to be seen if the advantage of a lowered lever in the first session extends into subsequent sessions (i.e., facilitates shock avoidance acquisition). Experiment 2 was directed to this issue, using a new sample of rats in an attempt to replicate, as well as to extend, the results of Experiment 1.

\section{EXPERIMENT 2}

\section{Method}

Subjects and Apparatus. The subjects were 22 female hooded rats obtained from Blue Spruce Farms, New York. The rats were experimentally naive and weighed about $160 \mathrm{~g}$ at the beginning of the experiment. Eight rats were trained with the lower lever (Group LL) and 14 rats were trained with the regular lever (Group RL). More rats were assigned to Group RL, as they formed a training group for a subsequent experiment. The equipment described in Experiment 1 was used in Experiment 2.

Procedure. The procedure outlined in Experiment 1 was followed in Experiment 2 with two exceptions: The shockpostponement interval was $15 \mathrm{sec}$, and 15 60-min avoidance training sessions were given.

\section{Results and Discussion}

First-session analyses. The differences in response rate between the two groups in the first session were unreliable $(\mathrm{t}<2)$, but the mean shock rate for Group LL was significantly less than that of Group RL (7.23 and 9.88 shocks $/ \mathrm{min}$, respectively) $[\mathrm{t}(20)=3.08$, $\mathrm{p}<.01]$. Moreover, Group LL showed a shorter latency to the first response than did Group RL (means of 35 and $173 \mathrm{sec}$, respectively) [ $\mathrm{t}(20)=4.37, \mathrm{p}<.01]$. The time elapsing between the first two responses of the session was less for Group LL $(37 \mathrm{sec})$ than for Group RL $(130 \mathrm{sec})$ [ $\mathrm{t}(16)=2.27, \mathrm{p}<.05]$; this analysis excluded four rats of Group RL that failed to make a response during the $10-\mathrm{min}$ recording period.

Across-session analyses. The response and shock rate data for each rat were arranged into five blocks of three sessions each and analyzed by a 2 by 5 ANOVA (with lever height and blocks of sessions as the factors) for unequal group sizes (Winer, 1962). These data are given in Figure 2. A significant increase in response rate over sessions was found $[F(4,90)=65.35, p<.001]$, but the overall response rates for Groups LL and RL (means of 8.0 and 7.7 responses/min, respectively) did not differ; the Groups by Sessions interaction also was not signifi-

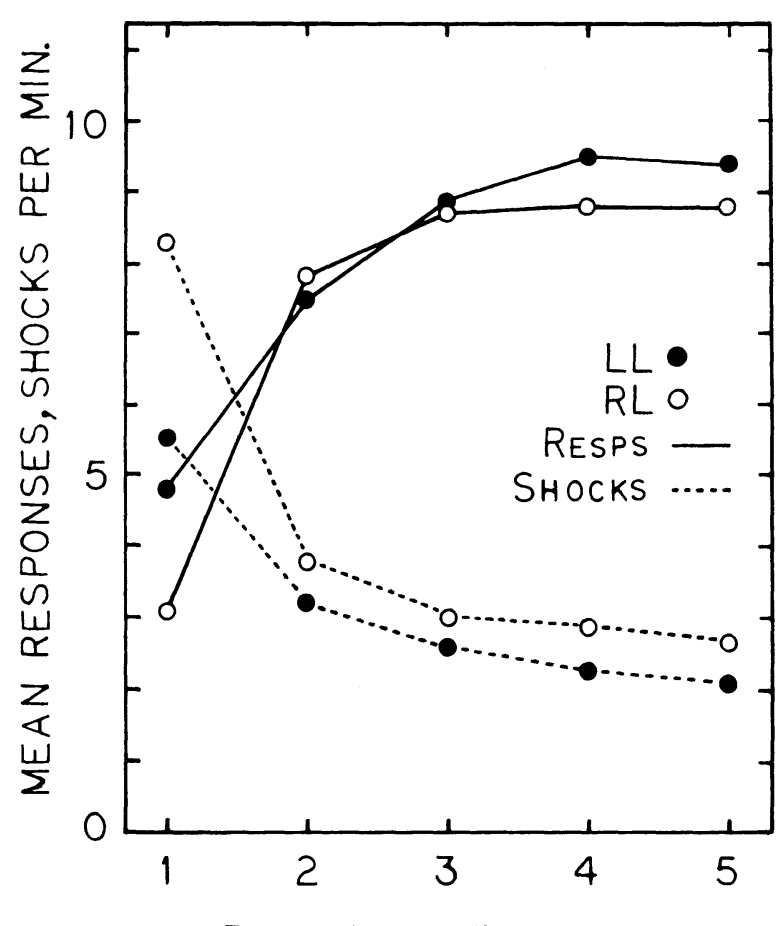

\section{BLOCKS OF 3 SESSIONS}

Figure 2. Mean response rates and shock rates over the 15 avoidance training sessions for the lower lever and regular lever groups (LL and $R L$, respectively).

cant. The reduction in shock rate for Group LL was less than for Group RL (means of 3.14 and 4.16, respectively) $[\mathrm{F}(1,20)=5.19, \mathrm{p}<.05]$. A significant Group by Session interaction was obtained $[\mathrm{F}(4,90)=11.99$, $\mathrm{p}<.001]$, and Sheffé tests indicated that the two groups differed only on the first block of sessions $(p<.001)$. An analysis of each session in the second block indicated that significant differences between the two groups had disappeared on Session 5. At the end of the experiment, an identical proportion of rats from each group (38\%) were receiving more than 3 shocks/ min (i.e., reflecting shock-elicited rather than shockpostponement behavior).

The analyses given above were based on measures obtained from the entire 60-min session. But over the final three sessions, response and shock frequencies in the first $15 \mathrm{~min}$ of each session were recorded and averaged for each rat as an index of "warm-up" performance. Group differences in response frequencies during warm-up only approached significance $[\mathrm{t}(20)=$ $1.92, \mathrm{p}<.10$ ], but Group LL received reliably fewer warm-up shocks than Group RL (means of 47 and 66, respectively) $[t(20)=2.96, p<.01]$. But as the earlier analyses showed, the difference in the shock measure disappeared over the remainder of the session.

\section{GENERAL DISCUSSION}

In the two experiments described above, rats were required to leverpress to avoid shock using a lever either in a "regular" or a "lowered" position (Groups RL and LL, respectively). 
In each experiment, several measures from the first session seemed to favor the lowered lever. That is, placing the lever close to the grid floor led to earlier first contacts with the lever (the latency measure) and to less time passing between the first and second response. Thus, lowering the lever increased the likelihood that the lever would be activated to interrupt the series of shocks delivered by the S-S interval (as reflected in the shock rate measures). The rats in Group RL, on the other hand, tended to run under or around the lever early in the session. From this context, the results harmonize nicely with the analysis of avoidance acquisition presented by Bolles (1970, 1971).

However, the finding that the response rates of the two groups were comparable suggests that the advantage given to Group LL by the lowered lever quickly faded even within the first session. With additional training (Experiment 2), shock rates soon were comparable (by the fifth session), and both groups showed similar acquisition curves. The only difference found between the two groups in the later stages of training was that Group LL received fewer shocks during the warm-up period. Our observations also indicated that the rats of both groups frequently engaged in lever-oriented locomotions to activate the lever (cf. Roberts, et al., 1977). Taken collectively, the outcomes of the two experiments are consistent with the report of Feldt and McCann (1977): The height of the lever offers little substantive influence over the mastery of leverpress avoidance, at least with a $1-\mathrm{mA}$ shock.

The question remains as to why the initial advantage with the lower lever was not maintained. Part of the answer, we suggest, lies in the development of leverpress avoidance that seems to follow three stages. The first involves the "discovery" of the lever. Within this stage a variety of responses in the rat's repertoire (e.g., running, freezing, jumping, biting the grids) compete, usually successfully, with the leverpress. Most leverpress responses in this stage occur long after the R-S interval has elapsed (i.e., within the S-S interval). In the second stage, leverpresses generally are initiated by shocks delivered at the end of the R-S interval (i.e., shocks programmed by an S-S interval become infrequent). In this stage the leverpress has become the prominent reaction to shock rather than the various natural defensive reactions. In the third stage, leverpresses become less bound to shock delivery and occur more often within the R-S interval (thus postponing shock).

Within this three-stage view, the lower lever facilitated passage through Stage 1 into Stage 2 but offered little advantage in progressing from Stage 2 into Stage 3. Indeed, a lowered lever may be cataloged with many of the factors noted earlier as "facilitating the acquisition" of leverpress avoidance (cf. Leaf, 1965; Stone, 1966), but which actually may serve to expedite the appearance of Stage 2 rather than influence Stage 3. We should note that, even if Stage 2 is attained (quickly or not), the transition into Stage 3 is not guaranteed (cf. Ellen \& Wilson, 1964; Roberts, 1978). Thus, inducing the rat to make contact with the lever and inducing the rat to use the lever to postpone shock are separate propositions and may, as Bolles (1971, p. 200) noted, involve different processes.

\section{REFERENCES}

Bolles, R. C. Species-specific defense reactions and avoidance learning. Psychological Review, 1970, 77, 32-48.

Bolles, R. C. Species-specific defense reactions. In F. R. Brush (Ed.), Aversive conditioning and learning. New York: Academic Press, 1971.

Bolles, R. C., \& Popp, R. J., JR. Parameters affecting the acquisition of Sidman avoidance. Journal of the Experimental Analysis of Behavior, 1964, 7, 315-321.

Ellen, P., \& Wilson, A. S. Two patterns of avoidance responding. Journal of the Experimental Analysis of Behavior, 1964, 7, 97-98.

Feldt, R. C., \& McCann, L. I. Defensive responding and leverpress topography compatibility: Effects of shock intensity, S-S interval, and lever position. Animal Learning \& Behavior, 1977, $5,78-82$.

Grossen, N. E., \& Kelly, M. J. Species-specific behavior and acquisition of avoidance behavior in rats. Journal of Comparative and Physiological Psychology, 1972, 81, 307-310.

Hayes, W. A., \& MacKinnon, R. C. Two methods of increasing response rate in free operant avoidance conditioning. Psychonomic Science, 1968, 13, 275-276.

Hineline, P. N. Warmup in free operant avoidance as a function of the response-shock $=$ shock-shock interval. Journal of the Experimental Analysis of Behavior, 1978, 30, 281-291.

LEAF, R. C. Acquisition of Sidman avoidance responding as a function of S-S interval. Journal of Comparative and Physiological Psychology, 1965, 59, 298-300.

Powell, R. W. Free operant (Sidman) avoidance in field-raised and laboratory-raised wild rats. Journal of Comparative and Physiological Psychology, 1971, 75, 216-225.

RiEss, D. Shuttleboxes, Skinner boxes and Sidman avoidance in rats: Acquisition and terminal performance as a function of response topography. Psychonomic Science, 1971, 25, 283-286.

RoBERTS, A. E. Free operant avoidance behavior of hooded rats: Some notes on within- and between-session stability. Psychological Record, 1978, 28, 253-262.

Roberts, A. E., Cooper, K. G., \& Richey, T. L. Rat behaviors during unsignaled avoidance and conditioned suppression training. Bulletin of the Psychonomic Society, 1977, 9, 373-376.

Roberts, A. E., Porter, J. W., \& Porter, A. G. Stability of behavior in rats over 120 free operant avoidance sessions. Psychological Reports, 1974, 34, 927-930.

Sidman, M. Avoidance conditioning with brief shock and no exteroceptive warning signal. Science, 1953, 118, 157-158.

Stone, G. C. Some factors that influence acquisition of free operant avoidance behavior. Psychological Reports, 1966, 18, 383-396.

Wine R, B. J. Statistical principles in experimental design. New York: McGraw-Hill, 1962.

\section{NOTE}

1. In some cases, the metric values given were calculated from information presented in the published article.

(Received for publication October 22, 1979.) 